\title{
Designing Journalists: Teaching Journalism Students to Think Like Web Designers
}

\author{
Bradford Gyori \& Mathew Charles
}

Journalism \& Mass Communication Educator 1-18

\begin{abstract}
The authors introduced 80 university-level journalism students to a web design program called Klynt and supervised the creation of multiple interactive documentaries. They discovered that fledgling reporters could effectively design interactive media while creating work that reflects their own candid and extemporaneous ethos. Building on the insight that journalism in the digital age must give rise to modified best practices, this study examines the complex production processes from which multiple idocs emerged. The authors conclude by suggesting four tentative "new best practices" for journalists attempting to think and act like web designers.
\end{abstract}

As professional roles and skills are being redefined by the digital age, "convergence" has become the watchword of the day (Veseling, 2000). However, as both genres and disciplines begin to merge, mere flexibility is no longer sufficient. Innovation has become key. Indeed, as Angus and Doherty (2015) explain,

To survive, journalism practice needs to adapt. This means the next generation of graduates must understand, and be able to exploit, the digital platforms and networks that will emerge. At the junction of their practice and technological development is design. (p. 45, emphasis added)

Still many scholars have noticed a reticence on the part of journalists to fully embrace the practical demands of digital journalism.

In recent years, journalism teachers have attempted a number of creative interventions, teaming their students with interactive designers (Angus \& Doherty, 2015), having them co-create wiki articles (Hoewe, Bowe, \& Zeldes, 2012), or facilitating internships with new media professionals (Madison, 2014). The author's approach was even more direct. In the spring of 2015, we tasked 80 universitylevel journalisms students with creating interactive documentaries. Assisting them in this endeavor was Klynt, a French-made software program that allows users to create branching and linking narratives without writing any code. Klynt also generates meta-data that can be copied and pasted into a variety of different web platforms. These features allowed students to create, modify, and share interactive content with relative ease. In many respects, acquiring new technical skills turned out to be less of a challenge for these fledgling journalists than adopting and innovating best practices appropriate for the task at hand.

Despite such concerns, it is important to stress that the unit the authors were super- vising is part of a degree in multimedia journalism and, therefore, the enrolled students had already mastered a wide range of digital skills. Broadcast and multimedia journalism undergraduates at our university are required to learn WordPress, Photoshop, InDesign, as well as audio and video editing, so they are familiar with the principles of page layout and web design. Still, creating the interactive documentaries was one of the most daunting challenges they had yet faced. Acquiring new technical skills presented some difficulties, but the bigger challenge involved a conflict between traditional journalistic practice and the demands of effective web design. After all, these students had to do more than simply report the news; they had to create a news interface with branching pathways for their audience to explore. This meant rethinking traditional notions of authorship and discovering new and effective ways to engage with online users. 
The following pages detail how this collaborative project was structured, the methods used to track student engagement, and the insights gleaned from these findings that can help to inform future pedagogy in this area.

\section{Method}

The i-doc project required 80 student-participants to work in randomly selected teams of four to five. A total of 16 interactive documentaries were created. Students assumed a variety of roles including social media producer, interface designer, project manager, and content producer. Because the projects were nonlinear, there was no specific time or size limit. While there were no rigid requirements regarding the incorporation of particular types of media, the students were encouraged to incorporate a wide range of media formats including video, stills, graphics, audio files, animations, text, web links, and social media forums. Also each project needed to be showcased to the instructors during a half-hour inclass presentation exploring all key narrative paths. In addition, students were prompt to reflect on what they had learned and to consider how the process transformed their approach to producing journalism.

All of the participants were second-year broadcast multimedia students enrolled on the course. They were asked to fill out a survey for this research study that kept all feedback anonymous. It included both quantitative multiple-choice questions and qualitative written-answer questions. In addition, students were given the option of opting out of the research survey. Still $74 \%$ of them responded. We have included only the work of students who consented to have their projects featured in this study. In addition to the survey, the authors observed student collaborations, pitches, and presentations and informally debriefed students throughout the process.

The first questions on the survey were based on the Likert-type scale with 1 equaling strongly disagree and 5 equaling strongly agree (Table 1).

\begin{tabular}{|l|l|}
\hline \multicolumn{1}{|c|}{ Prompt: } & Mean: \\
\hline The unit was stimulating and challenging. & 4.84 \\
\hline The workshops were interesting/accessible. & 4.72 \\
\hline The unit was stimulating and challenging. & 4.84 \\
\hline The workshops were interesting/accessible. & 4.72 \\
\hline I have a better understanding of web design as a result of this unit. & 3.72 \\
\hline I have a better understanding of non-linear narratives as a result of unit. & 4.57 \\
\hline I have produced original journalism as part of this unit. & 4.21 \\
\hline Klynt has enabled me to produce innovative and cutting-edge work. & 3.21 \\
\hline
\end{tabular}

Table 1. Student Webdoc Creation Survey Results

Some of the questions on the survey were standard course satisfaction queries, but we also prompted students to consider what they had learned about web design. In particular, we were interested in learning how the project challenged them to adopt new professional practices and to rethink their relationship to the audience. Clearly, most of the students enjoyed rising to the challenges presented by the i-doc assignment. Yet to complete this project successfully, they had to master more than new technical skills, they had to start thinking and acting like web designers. This presented some significant methodological challenges, which may explain why their writ- ten responses to the survey were a bit mixed:

"This unit was great. Made me think and I learned new skills.”

"Unit was too rushed. Needs to be longer."

"The best unit on the degree so far."

"There should have been more instruction to guide us through each stage of the process as the project was so new to us." 
"Klynt has too many problems."

"I think this unit has made me more employable. This is what news organizations are trying to do more of and now I have the skills to offer them."

“Too complicated. Can’t see where or why journalists would be involved in actual programming anyway."

"Great to think about the audience and the user experience. Could really be creative, though we did not have the skills to match our ideas."

"Klynt was very limited for what we wanted to do."

"I learned so much in this unit. Content was new, and I was able to use and combine skills learned in other units."

"Challenging, but worth it."

These comments confirm what the instructors observed in workshop sessions and in the final i-doc presentations. Acquiring new technical skills presented some difficulties, but the bigger challenge involved a conflict between traditional journalistic practice and the demands of effective web design. Here are some of the areas were those tensions were most pronounced.

\section{Workflow}

The students frequently struggled with the notion that generating effective web design requires methodical trial and error experimentation. Live television broadcasts and real-time news day drills had encouraged them to produce media quickly and decisively. Now they were being asked to slow down and create interactive documentaries, not in a single day, but over the course of several weeks. The slow, repetitive demands of web design struck many of them as tedious, creating a temptation to cut corners. Accustomed to delivering a finished product at the last minute, some put off organizing their materials until a few days before the deadline, but these projects were not breaking news stories to be hammered out at the 11 th hour; they were immersive interfaces requiring extensive refinement. Even the long-form features they had previously produced had not prepared them for the rigors of a workflow that required immediate prototyping followed and step-by-step modification.

Another tension emerged around the issue of autonomy. According to Boyd (2001), the ideal reporter "should be self-reliant and capable of working with a minimum of guidance and supervision" (p. 4). Traditional news journalists jealously guard confidentiality, disclosing very little about their works-inprogress. Content is never sub- mitted to the audience ahead of publication. In fact, many reporters struggle with handing over their work to sub-editors!

In contrast, web designers depend on the influence of others and must actively seek feedback throughout the production process via user testing. This means allowing their projects to be evaluated while they are still evolving, hence the oft-repeated web design mantra, "fail early, fail often" (Figure 1).

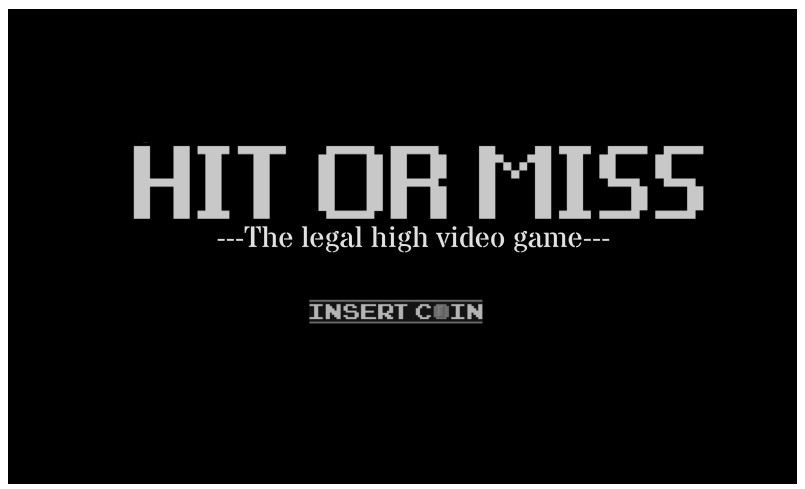


Figure 1. Hit or Miss: Testing and iteration. (Brown, Hastie, Jackson, \& Pegg, 2015)

The authors are only aware of one team engaging in extensive user testing. These were the creators of Hit or Miss (Brown, Hastie, Jackson, \& Pegg, 2015), a look at various intoxicating substances being sold over-the-counter. This team said their primary motivation for seeking peer feedback involved testing the gaming elements of their project to insure that they were not too easy. The extra effort paid off, helping them fine-tune the project and create an immersive multimodal interface.

\section{Structure}

Many of the student i-docs featured a fair amount of hidden or partially obscured content. This raised another central tension: games require users to seek out content and rewards. In contrast, journalism strives to convey information openly and efficiently. So for these aspiring reporters, hiding content from users felt counterintuitive. One of them explained it this way: "As a journalist I want everyone to have access to all of my story, so to have to hide some of it felt wrong. Sometimes I was even uncomfortable that making our project a game was trivializing the issue."

Striking the correct balance between traditional authorship and digital interaction was one of the biggest challenges for students. They had been taught that the "leader" of a story must answer the 5 W's: who, where, what, when, and how (Stovall, 2004). And they had practiced writing in the inverted pyramid style with the most important information visible at the top of each piece (Hudson \& Rowlands, 2012). Now they were attempting to create a story with multiple entry and exit points and with numerous routes between them. This required extensive planning and new conceptualization of story itself.

In the spirit of this complex narrative approach, the opening lecture outlined five interactive storytelling structures: branching, fishbone, parallel, threaded, and concentric (Maurin, 2014). Drawing on these structures, and utilizing the Klynt software, each team constructed a narrative overview called a "mind map" (Figure 2).

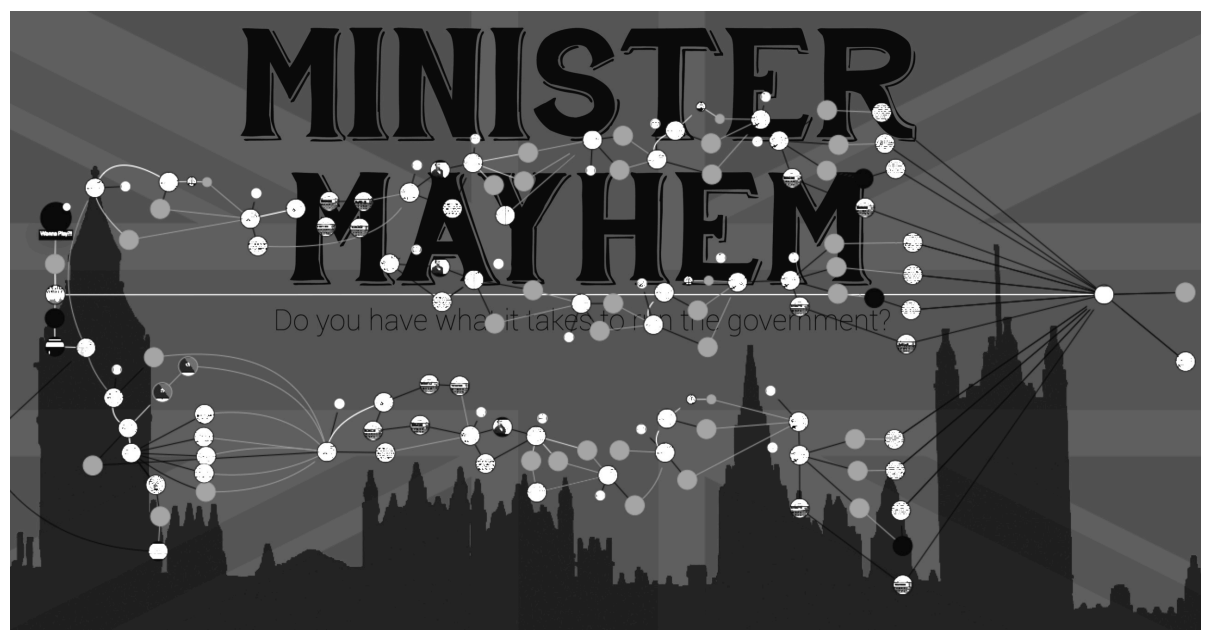

Figure 2. Minister Mayhem: Branching structure. (Allen, Bailey, \& Quarcoo, 2015)

The students that opted for a branching structure, created narratives that started out in a linear fashion, and then reached key decision points where they bifurcated into two or more forking paths. The mind maps designed in this way grew to resemble an organic configuration such as a tree or rhizome (Figure $3)$. 


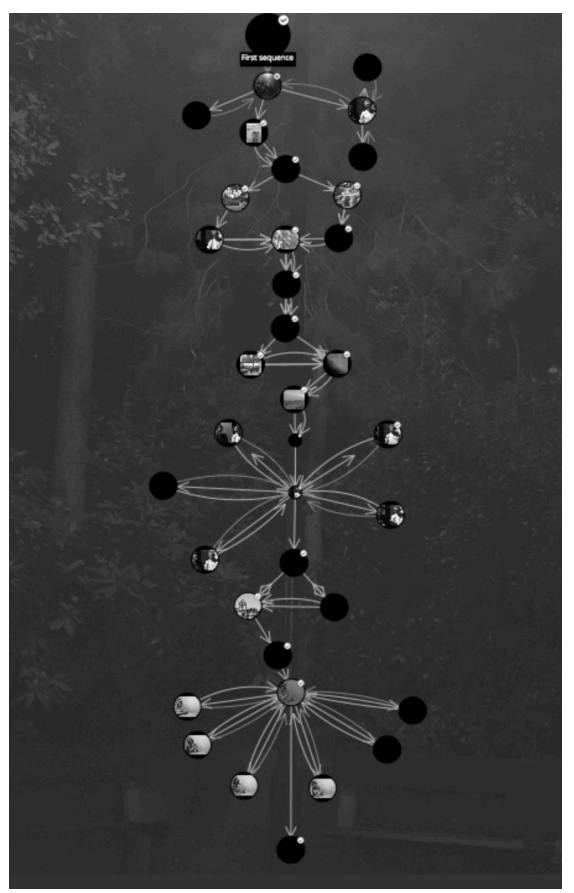

Figure 3. In Their Shoes: Fishbone structure. (Clive, Elias, Millard, \& Veryard, 2015)

The more tightly constrained fishbone structure allowed students to hew to a single narrative spine. Story elements could occasionally jut off on temporary tangents but always quickly gravitated back to the familiar linear progression at the center of the interface (Figure 4).

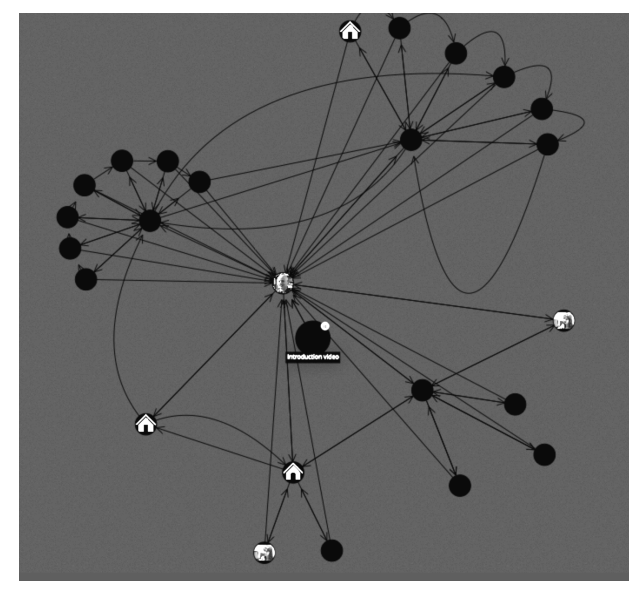

Figure 4. Anxiety in the City: Concentric structure. (Belcher, Bunker, Clarke, Marshall-Bell, \& Walters, 2015)

The concentric structure employed by some of the students featured a constellation of loosely configured informational nodes. By clicking on one of these figures at random, the user could unlock a unique story element. Like the traditional African narratives that Jennings (1996) compares to many new media forms, this interface is cyclical and nonlinear. It also oscillates between macrocosm and microcosm, forest and trees, giving users a glimpse of the big picture and then allowing them to drill down into specific details (Figure 5). 


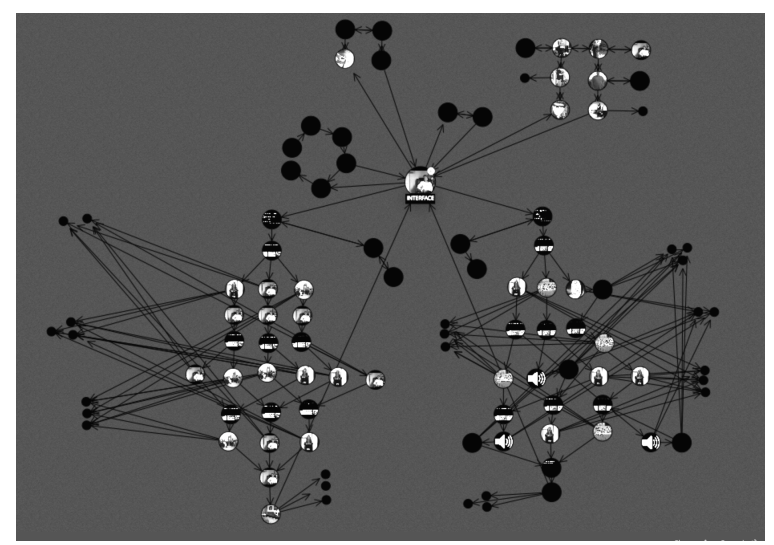

Figure 5. The Fight Against Food: Hybrid structure-Concentric \& branching. (Foster, Hargood, Hatcher, \& Mileham-Chappell, 2015)

From the start, the students were encouraged to experiment and innovate. One of the more inventive designs was a hybrid of both concentric and branching structures. In this case, the student team started with an array of discrete nodes but then found inventive ways to connect them. The resulting configuration was part free-floating constellation/part entwined network.

\section{Interface}

Learning to think like a web designer means shifting from pilot to planner, stepping out of the driver's seat and creating an array of potential pathways. This shift of focus meant our journalism students could no longer dictate the flow of the story. Instead, they were compelled to focus on the meta-skills involved in affording multiple opportunities for others to get behind the wheel and explore. This involved both an objective and a subjective dimension.

A hallmark of good web design is the creation of an "intuitive" interface (Baxter \& Courage, 2005). This is the objective dimension of web design. It involves arranging content in a simple and straightforward manner with the average user in mind. Because the students were employing relatively rudimentary web design tools, merely linking and branching between different bits of digital content, the interfaces they created tended to meet the objective requirement. In some cases, they were perhaps a bit too rudimentary, offering up bits of content like confections on a tray that the user could click on and view one by one, or sniff at and move past.

In the most general terms, the interfaces came in three flavors.

1. Linear: users can control the pacing and to some extent the order of presentation, skipping ahead, or moving back, but the elements are always arranged in a continuous sequence.

2. Linear + nonlinear: linear content with a few tangents or branches available.

3. Nonlinear: the user is in complete control of order and pacing. There is no fixed ending.

Our student teams experimented with all three of these approaches and discovered that each presented new creative opportunities and challenges (Figure 6).

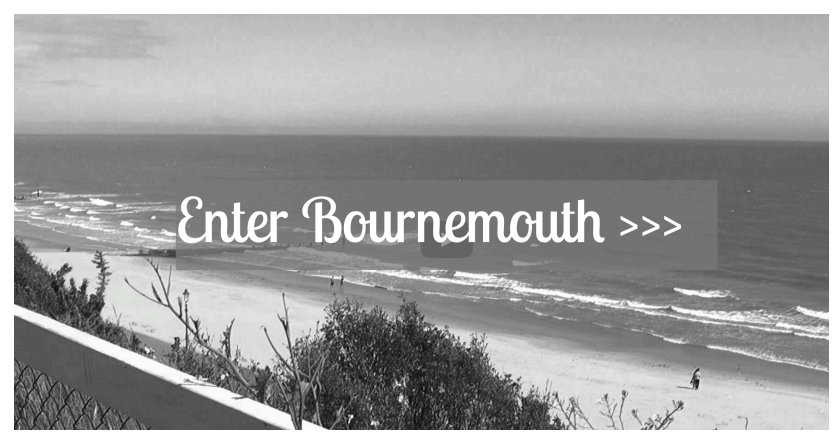


The chief advantage of the linear approach is control. It tightly constrains the user's options to just a few: stay put, move forward, skip forward, move back, or skip back. Thus, linearity is a good tool to employ when conveying key bits of information at crucial times. However, this degree of control has its disadvantages as well. One student misunderstood that linearity was just one of many interactive options and created an exclusively linear design, a sort of daisy chain approach, linking elements in a simple unbroken sequence. The result was no more interactive than leafing through the pages of a magazine, so the interface was not particularly engaging (Figure 7).

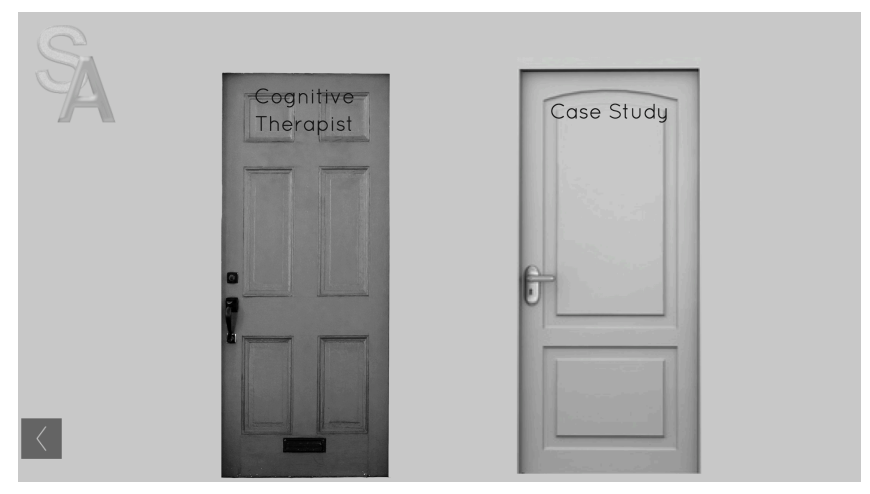

Figure 7. Social Anxiety: Linear/nonlinear. (Bird, Farnan, Harry, Ng'ethe, \& Poduval, 2015)

Fortunately, the rest of the student teams included some elements of nonlinearity. For instance, many experimented with some form of branching narrative, designing bifurcation points where their linear narratives forked into two or more paths. Perhaps, it is appropriate that their reaction to this approach veered off in opposing directions. Some felt that, as producers, their story was being lost. As the projects became more interactive, the focus shifted to the interests and behaviors of the users. On the contrary, some were excited that whatever they produced could actually be more personal to the user/audience because of the required interaction. For them, a sense of heightened audience engagement helped to compensate for the loss of narrative control (Figure 8).
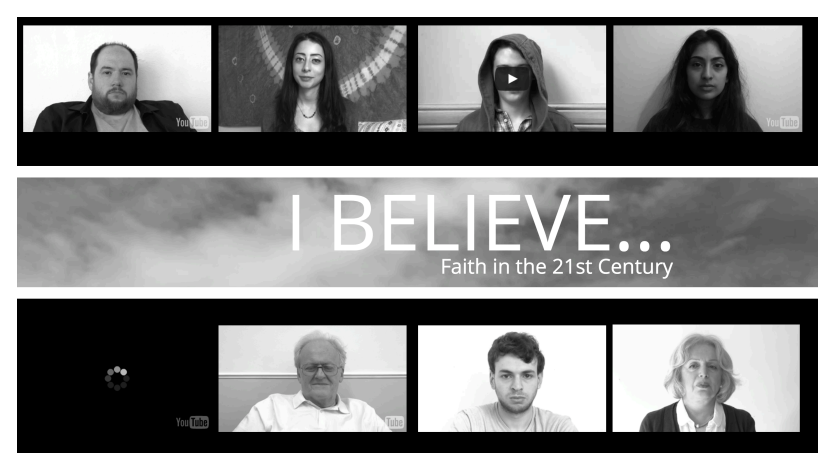

Figure 8. I Believe: Nonlinear. (Connor, Dixon, Foster, \& Tijou, 2015)

The most nonlinear approach involved presenting users with an array of hyperlinks. In the case of the webdoc I Believe (Connor, Dixon, Foster, \& Tijou, 2015), this design strategy created opportunities to look at the changing face of religion from a variety of theological perspectives. This meant users were encouraged to think critically and challenge the impulse to automatically privilege one view over another.

\section{Emergence}

After the links and branches of web interface, the path opens into a wide, loosely defined space with an even higher degree of complexity. This is the realm of emergence. Physicist Robert B. Laughlin (2006) defines emergence as "complex organizational structure growing out of simple rules" (p. 200). Flocks 
of birds and schools of fish are emergent systems. Likewise, patterns of online behavior both prosocial (citizen journalism, digital activism, crowdsourcing) and anti-social (mobbing, trolling, cyberbullying) are emergent phenomena.

Emergence can be volatile and unpredictable. After all, it is the root word of "emergency!" Because of this, journalists who wish to provide open forums for user-generated content must cautiously compose the simple rules that govern these complex ecosystems. Emergence is not merely a troublesome side effect of the digital age; it is a driving factor, a force that must be reckoned with (Park, 2007; Spyridou, Matsiola, Veglis, Kalliris, \& Dimoulas, 2013; Zeller \& Hermida, 2015).

While journalism has long invited audience engagement via letters to the editor and opinion polls, a journalist encountering the hydra-headed behemoth that is emergence is less of a gatekeeper than a kitten wrangler. This means, she must roll up her sleeves and wade into the clamor of competing voices, serving as a role model, a promoter, an architect, a standard bearer, and if necessary, a referee. Thus, as technology continues to collapse time and space restrictions and create new opportunities for sustained and pervasive interaction, news reporters must adapt. At its worse, this trend results in "churnalism," the careless dissemination of information gleaned from sources that have not been properly vetted without additional investigation or reflection (Davies, 2009).

As Gowing (2009) points out, the question of rapid-fire co-creation or "immediacy" is related to verification, as speed is often the enemy of accuracy. At its best, however, the relationship between journalists and their audience is respectful and mutually advantageous, forming a self-sustaining and self-correcting community called "the public" (Loosen \& Schmidt, 2012).

Constructing and curating open-ended, unbounded digital forums is one way that digital journalists can address the issue of emergence. This involves creating online environments where matters of public concern can be freely articulated and deliberated. It also means ceding some control of news content and sharing the ability to frame public perceptions of broad social issues. In the digital age, media users are co- creators and co-agenda setters (Herbert, 2000).

The student teams in this study grappled with emergence in different ways. Because of the tight 5-week time frame, none of them solicited user-generated content (though a longer schedule would have allowed for this as well). Some did include quizzes and votes. Other potential ways of channeling emergence that the teams did not exploit include embedding insta-polls, message boards, online surveys, wikis, and reflexive ranking systems.

Ironically, the team with the strongest social media presence created an i-doc about Social Anxiety (Bird, Farnan, Harry, Ng'ethe, \& Poduval, 2015). Unlike the people they interviewed, they were eager to engage with the public, compelling their audience to interact and engage via Twitter, Facebook, selfhelp apps, advice lines, and forums. When it comes to managing emergence, journalists must often choose between piggybacking on pre-existing discourses or attempting to create their own forum from scratch. The Social Anxiety team embedded established feeds within their i-doc. Including these sites allowed the team to connect their audience with larger on-going conversations related to their project. Yet beyond embedding the feeds, their contribution to external discussions was minimal. In contrast, the team that created the Working with Autism (Fiancet, Rigden, Shearing, Sukys, \& Wong, 2015) i-doc generated their own Twitter page in an attempt to establish a unique public. Each team member tweeted once, inviting others to follow the feed. At the time of this writing, 74 people were following but no comments and had been posted. What this team gained in terms of control-the ability to create and curate their own original feed - they lost in terms of relevance - the opportunity to host a lively far-reaching discussion.

It may be worth noting that neither team provided a rationale for why they preferred a particular mode of emergence, pre-fab or homegrown. This suggests a need for more scrupulous consideration of curating practices, a topic elaborated on the following and final section.

\section{Conclusion: 4 Best Practices for Journalism Students Designing I-docs}


To effectively capitalize on the promise of the digital age, journalists and journalism educators need to strategically modify traditional best practices, adapting them to a rapidly changing media environment. This study only focuses on the work of 80 students participating in a single course. Nonetheless, several recurring disciplinary challenges have been identified via student feedback and direct observation. Many of our groups had some very ambitious ideas to begin with. This perhaps showed a lack of understanding of design/programming, of what was actually possible. They had to be reigned in a bit. Students also struggled reconciling design thinking with the tenets of traditional journalism. One student wrote on his or her survey sheet: "As a journalist I want everyone to have access to all of my story so to have to hide some of it felt wrong. Sometimes I was even uncomfortable that making our project a game was trivializing the issue." Journalism students are used to telling stories with a headline, a beginning, a middle, and an end. Having to tell a story with multiple entry and exit points, and with varied routes between them, requires a different sort of planning. Some students rose to the challenge. Others left it too late and chose "easy" or "easier" ways out. Another theme/tension that arose was a loss of control. Some students felt that as producers their story was being lost, because the project was becoming more about the user. On the contrary, there was also excitement that whatever was produced could actually be more personal to the user/audience because of the required interaction.

As digital journalism requires increased engagement with new media design plat- forms, forwardthinking educators are beginning to focus on the creation of I-docs. It may be helpful, therefore, to sketch out some tentative best practices for the rapidly evolving subject of interactive documentary design.

\section{A.B.C. Testing}

One of this study's key findings was that journalism students struggle with the concept of user testing. News day drills culminating in same-day bulletins habituate them to the fast-paced tactics of traditional broadcast journalism. Effective web design, how- ever, demands a more methodical and transparent workflow. Because of this, designers engage in all sorts of user testing: usability, compatibility, regression, installation, smoke, sanity, acceptance, security, and so forth. The copious variety and ubiquity of user testing attest to its value. As Hambling and van Goethem (2013) state, "The importance of testing throughout the development of an IS [Interactive System] should not be underestimated ... There is a strong argument for getting the eventual users involved as early as possible and for keeping them engaged throughout development” (pp. 24, 25).

To mitigate the resistance of journalism students, the authors propose structuring key workshops around a three-stage testing process. These stages can be written into the class schedule along with deadlines, so that feedback is addressed and delivery is insured in a timely manner. During these sessions, i-doc teams will be required to invite students from other teams to navigate through iterations of their evolving project and provide immediate feedback. Instructors can both oversee and participate in this process, but much of the learning will be peer-to-peer, systematically reinforcing the vital importance of user testing. The A (or Alpha) stage will be a rough draft trial. The B (or Beta) stage will be a fine draft trial. And the $\mathrm{C}$ (or Complete) stage will be a final draft trial. Each of these phases will present opportunities to refine the work. Students should be encouraged to record audio files of spoken user feedback on their smart phones or laptops, or to have users fill out printed or electronic questionnaires. This information should prove invaluable in terms of improving their i-docs and will, hopefully, diminish any lingering resistance to the testing process.

\section{Hieratic Design}

Our students were not always sure what information to foreground and what information to place deeper within the interface. This is one of the most intriguing challenges related to the design of interactive journalism. Scholars agree that journalists structuring online content need not abandon concerns related to clarity, proportion, and priority. Instead, they must modify traditional practices so they become compatible with interactive and participatory modes of engagement (Hudson \& Rowlands, 2012; Sissons, 2006). The "inverted pyramid" is a tool for ordering informational hierarchies, but it is not the only means of accomplishing this. In the ancient world, artists ignored perspective in favor of a different mode of perception now known as "hieratic scale." Regardless of their position on the picture plane, powerful figures were depicted as physically larger than less 
influential beings. Describing this archaic design strategy, Lauer and Pentak (2007) write, "Often in the past, size was used to denote some conceptual importance and not to indicate how close or far away the figure was spatially" (p. 199).

This is not to suggest that effective design is merely a process of spotlighting figures of utmost importance. Actually, the best visual and narrative structures involve some degree of obfuscation. Hints are given and questions are raised with no immediate payoff necessary. The goal is to hook the audience and promote immediate engagement. However, once this is accomplished, orientation is paramount. The audience needs a clear sense of what matters and how much.

The inverted pyramid and hieratic scale are both means of achieving this crucial end. They are tools for ordering attention, directing the audience to what matters most. They can be seen as subsets of a larger category the authors call, "hieratic design." Promoting hieratic design involves insuring that key bits of information are made prominent through a wide array of tactics: the strategic manipulation of scale, sequence, accessibility, multiplicity, and the constraint of navigational choices. Rather than merely undermining and limiting authorial control, therefore, effective web design offers journalists a host of tools for conveying information in a clear and compelling manner.

\section{Affordance Authoring}

Whereas traditional journalism involves consciously directing the attention of one's audience, interactive journalism involves creating an array of choices for users to select from. Our students occasionally found it difficult to share authorial control, but gradually, discovered that interaction design promoted a different kind of creative process, one we call "affordance authoring."

Mastering digital journalism means designing interfaces that are both objectively intuitive and subjectively appealing. This resonates with the work of psychologist James J. Gibson (1979). According to Gibson, perception occurs at the crossroads of the objective and the subjective. What individuals focus on is related to what the world has on offer and what they seek to utilize and explore. Gibson termed these sites of potential engagement, "affordances," as in, a feature of the environment that affords a particular type of interface.

While a broadcast medium like television imposes stimuli on an audience, an affordance is a feature of the environment that the audience may or may not choose to engage with. What's more, a single affordance may offer different things to different users. A tree can afford climbing, nesting, or shade depending on one's abilities, needs, and desires. Donald Norman (2013) has written about the affordances of everyday objects such as teapots and lights switches and encourages fellow designers to consider the psychology behind how people engage with these items. According to Norman, an object with good affordances invites a clear and simple interface. A teapot with a clearly graspable handle and a light switch close to a door are examples of this.

Building on the work of Gibson and Norman, web designers frequently emphasize the importance designing effective online affordances, while keeping in mind their related constraints and demands (Rogers, Sharp, \& Preece, 2011). Students tasked with authoring affordances will be compelled to employ features such as branches, links, checkpoints, chokepoints, and Easter eggs in a manner that appeals to both general and specific audiences. In addition, the affordance concept can help them understand how their role has shifted from traditional narrative composition to interface design.

\section{Conscious Curation}

When incorporating social media into their i-docs, our student journalists often avoided thinking through curating practices. This, we feel, is a blind spot that can and should be eliminated with more careful critical analysis regarding the role of social media forums in relation to interactive content.

In the digital age, journalists are increasingly viewed as "content curators" and "community managers" (Bradshaw \& Rohumaa, 2011). They are tasked with guiding and vetting emergent content, but to what end and by what means? As Wallace (2013) points out, the journalistic value of news and opinion 
gleaned from social media is often suspect, blurring the line between public and private communication.

With this in mind, the authors propose a final best practice, "conscious curation." A traditional news periodical may publish a set of editorial principles for the staff to abide by when authoring articles. Likewise, student journalists can be tasked with incenting user engagement and then posting a short statement of "curation principles" along with embedded feeds, explaining how they intend to deal with content created by lay participants. What tactics will they employ and why? What are their metrics for success? Is merely garnering attention enough? If the quality and credibility of audience engagement is a concern, how will they determine this? Will they moderate discussions? If so, what will they censor? And how will those elements be identified and defined? Will they focus on prevention (i.e., blocking anonymous posts), reaction, (i.e., removing hate speech), or constraint, and guidance (i.e., inviting participation in surveys and polls)? Will they use pre-existing feeds or create their own and, if so, why? How will they negotiate the trade-off between exclusivity and inclusion, between standards and censorship? Will they promote dialogue and/or solicit user-generated content? If so, how and why? Moreover, will participants post anonymously or not and if so, to what end?

Whatever decisions the students make regarding curation, the discussions around these issues are bound to be productive. Student teams will be compelled to think through how the policies they have created tie journalistic ethics to the demands of a particular participatory discourse, considering how said procedures frame, shape, and channel the content that arrives once they release the emergence genie from the bottle.

To summarize, the four best practices outlined above are a starting point. The authors hope that they can help students begin to master effective design strategies while, nonetheless, adhering to key journalistic principles. Incorporating them into lesson plans and curriculum design may compel fledgling reporters make more thoughtful, creative, and efficient choices related to workflow, collaboration, structure, interface, and emergence. This approach will hopefully create opportunities for teachers to gain insights alongside students. As Royal (2004) insists regarding digital journalism education, "The instructor must view the course as a learning environment, not only for students but also for himself/her- self" (p. 411).

\section{References}

Allen, A., Bailey, R. \& Quarcoo, P. (2015). Minister Mayhem. Retreived from http://buzz.bournemouth. ac.uk/IntDoc/Minister_Mayhem/

Angus, D., \& Doherty, S. (2015). Journalism meets interaction design: An interdisciplinary undergraduate teaching initiative. Journalism \& Mass Communication Educator, 70, 44-57. Baxter, K., \& Courage, C. (2005). Understanding your users: A practical guide to user require- ments methods tools and techniques (interactive technologies). Burlington, MA: Morgan

Kaufmann.

Belcher, D., Bunker, J., Clarke, J., and Marshall-Bell, C \& Walters, J. (2015). Anxiety in the City.

Retreived from http://buzz.bournemouth.ac.uk/IntDoc/Anxiety_in_the_City/\#Introduction_

video

Betts, J., Cain, R., Cottrell, J., \& Jones, C. (2015). Digital economies. Retrieved from http://

buzz.bournemouth.ac.uk/IntDoc/Digital_Economies/\#Introduction

Bird, A., Farnan, B., Harry, R., Ng'ethe, P., \& Poduval, A. (2015). Social anxiety. Retrieved

from http://buzz.bournemouth.ac.uk/IntDoc/Social_Anxiety/

Boyd, A. (2001). Broadcast journalism: Techniques of radio and television news. Oxford, UK:

Focal Press.

Bradshaw, P., \& Rohumaa, L. (2011). The online journalism handbook: Skills to survive and 
thrive in the digital age. Edinburgh Gate, UK: Pearson Education.

Brown, C., Hastie, A., Jackson, H., \& Pegg, S. (2015). Hit or miss. Retrieved from http://buzz.

bournemouth.ac.uk/IntDoc/Hit_or_Miss/\#Web_Doc Intro

Clive, J., Elias, B., Millard, D., \& Veryard, C. (2015). In their shoes. Retrieved from http://buzz.

bournemouth.ac.uk/IntDoc/In_their_shoes/\#First_sequence

Connor, B., Dixon, S., Foster, M., \& Tijou, S. (2015). I believe. Retrieved from http://buzz.

bournemouth.ac.uk/IntDoc/I_believe/

Davies, N. (2009). Flat earth news: An award-winning reporter exposes falsehood, distortion

and propaganda in the global media. New York, NY: Vintage.

Fiancet, A., Rigden, A., Shearing, L., Sukys, A., \& Wong, H. (2015). Working with autism.

Retrieved from http://buzz.bournemouth.ac.uk/IntDoc/Working_with_Autism/\#Home

Foster, J., Hargood, H., Hatcher, L., \& Mileham-Chappell, M. (2015). The fight against food. Retrieved from http://buzz.bournemouth.ac.uk/IntDoc/The fight against food/\# INTERFACE

Gibson, J. J. (1979). The ecological approach to visual perception. New York, NY: Psychology Press.

Gowing, N. (2009). "Skyful of lies" and black swans. Oxford, UK: Reuters Institute for the Study of Journalism. Retrieved from http://reutersinstitute.politics.ox.ac.uk/publications/risj-challen-ges/skyful-of-lies-blackswans.html

Hambling, B., \& van Goethem, P. (2013). User acceptance testing: A step-by-step guide. London, England: BCS, The Chartered Institute for IT.

Herbert, J. (2000). Journalism in the digital age: Theory and practice for broadcast, print and online media. Oxford, UK: Focal Press.

Hoewe, J., Bowe, B. J., \& Zeldes, G. A. (2012). Using a Wiki to produce journalistic best prac- tices. Communication Teacher, 26, 22-32.

Hudson, G., \& Rowlands, S. (2012). The broadcast journalism handbook (2nd ed.). Edinburgh Gate, UK: Pearson Education.

Jennings, P. (1996). Narrative structures for new media: Towards a new definition. Leonardo, 29, 345-350.

Lauer, D. A., \& Pentak, S. (2007). Design basics. Belmont, CA: Wadsworth.

Laughlin, R. B. (2006). A different universe: Reinventing physics from the bottom down. New

York, NY: Basic Books.

Loosen, W., \& Schmidt, J. H. (2012). (Re-)discovering the audience. Information,

Communication \& Society, 15, 867-887.

Madison, E. (2014). Training digital age journalists: Blurring the distinction between students

and professionals. Journalism \& Mass Communication Educator, 69, 314-324.

Maurin, F. (2014, October 18). Creating non-linear narratives. Presentation Given at MIDBO,

Bogot, Colombia.

Norman, D. (2013). The design of everyday things (Rev. ed.). New York, NY: Basic Books. Park, J. Y. (2007).

Empowering the user as the new media participant. Digital Creativity, 18,

175-186.

Rogers, Y., Sharp, H., \& Preece, J. (2011). Interaction design: Beyond human-computer inter- 
action. Hoboken, NJ: John Wiley.

Royal, C. (2004). Teaching web design in journalism and mass communications programs:

Integration, judgment, and perspective. Journalism \& Mass Communication Educator, 59,

399-414.

Sissons, H. (2006). Practical journalism: How to write news. London, England: SAGE. Spyridou, L. P., Matsiola, M., Veglis, A., Kalliris, G., \& Dimoulas, C. (2013). Journalism in a

state of flux: Journalists as agents of technology innovation and emerging news practices.

The International Communication Gazette, 75, 76-98.

Stovall, J. G. (2004). Journalism: Who, what, when, where, why, and how. Cambridge, MA:

Pearson.

Veseling, B. (2000, November). Flexibility the key in the multimedia world. FANFA Bulletin,

pp. 20-23.

Wallace, S. (2013). Impartiality in the news. In K. Fowler-Watt \& S. Allan (Eds.), Journalism:

New challenges (pp. 64-78). Bournemouth, UK: Centre for Journalism and Communication

Research Bournemouth University.

Zeller, F., \& Hermida, A. (2015). When tradition meets immediacy and interaction the integra-

tion of social media in journalists' everyday practices. About Journalism, 4, 106-119.

\section{Author Biographies}

Bradford Gyori is a senior lecturer in Digital Storytelling at Bournemouth University. As a television writerproducer, he has worked for MTV, VH1, FX, E! and HBO online, and for ten years, he was the Head Writer of the Emmy award winning Talk Soup. He holds a PhD in Rhetoric and Composition from ASU, his research focuses on interactive narratives, and his articles have appeared in Interactive Storytelling, The Journal of Broadcasting and Electronic Media, Journalism Education, The Interdisciplinary Journal of Problem-based Learning and Flow.

Mathew Charles is an award-winning documentary film-maker and senior lecturer in journal- ism and documentary in the School of Journalism, English and Communication at Bournemouth University. He was a presenter on BBC World and BBC Three, has reported extensively across Europe, and has also worked for flagship programmes, Newsnight, Today, BBC Breakfast and the BBC News Channel. He teaches courses in broadcast journalism, documentary, digital storytelling, news theory and comparative politics. 